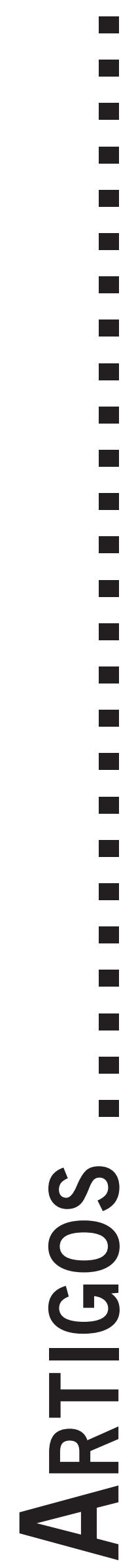




\title{
ANALOGIAS E DIFERENÇAS ENTRE REUNIÕES MEDIÚNICAS ESPÍRITAS E O ATENDIMENTO EM PSICOLOGIA CLÍNICA
}

\author{
The Spiritist Mediumnic Appointments and Their Relations with the Clinical Psichology \\ Las Reuniones Mediumnicas Espíritas y su Relaciones con la Psicología Clínica
}

Silvia Regina Vergilio

Adriano Furtado Holanda

\begin{abstract}
Resumo: A prática de realizar reuniões mediúnicas é comum a diversas religiões no Brasil, mais particularmente no Espiritismo Kardecista. Nesse contexto, as reuniões têm como objetivo auxiliar espíritos que se comunicam por meio de médiuns através do diálogo, nos moldes de um aconselhamento religioso. Apesar de ter seu espaço na cultura brasileira, essa prática religiosa tem sido pouco investigada na literatura psicológica e isto serviu como motivação para o presente trabalho que tem como objeto de estudo as reuniões mediúnicas e suas inter-relações com a psicologia clínica. A partir do registro observacional de uma reunião mediúnica, buscou-se sua caracterização para compreender suas articulações com o sofrimento humano e a Psicologia. Como resultado observa-se que há muitas similaridades de técnicas adotadas pelo dirigente da reunião e o psicólogo clínico, e que a linguagem religiosa constitui um instrumento privilegiado de diálogo. Entender essa linguagem pode auxiliar os psicólogos a lidar adequadamente com o fenômeno da mediunidade durante o processo terapêutico.

Palavras-chave: Psicologia da Religião; Aconselhamento Psicológico; Fenomenologia; Espiritismo.
\end{abstract}

\begin{abstract}
Mediumnic appointments are a common practice in diverse Brazilian religions, particularly the Kardecist Spiritism. In this context, the appointments have the goal of helping spirits, who speak through a medium during dialogs, similarly to a religious counseling. Spite of its space in the Brazilian culture, this religious practice has been few investigated in the psychological literature, and this fact is a motivation to the present work, which has as study subject the mediunic appointments and their interrelations with the clinical Psychology. From an observational register of a mediumnic appointment, its characterization was obtained to better understand its articulations with the human suffering and Psychology. As a result of this work it was observed that there are many similarities in the techniques adopted by the leader of these appointments and the clinical psychologist. In addition to this, the religious language is a privileged instrument for dialogue. To understand this language can help psychologist to deal properly with the mediumnic phenomenon during the therapeutic process.
\end{abstract}

Keywords: Psychology of Religion; Psychological Counseling; Spiritism; Clinical Psychology.

Resumen: Reuniones mediumnicas son una practica muy común en diversas religiones en Brasil, mas específicamente en el Espiritismo Kardecista. En este contexto, las reuniones tienen como objetivo auxiliar espíritus que se comunican por medio de mediums a través de dialogo, similarmente a un aconsejamiento religioso. A pesar de tener su espacio en la cultura brasileña, esta practica religiosa ha sido poco investigada na literatura sicológica y esto sirvió como motivación para el presente trabajo que tiene como tema de estudio las reuniones mediumnicas y sus inter-relaciones con la psicología Clínica. A partir del registro observacional de una reunión mediumnica, se busco su caracterización para comprender sus articulaciones con el sufrimiento humano y con la psicología. Como resultado de este trabajo, se observo que existen muchas semejanzas de las técnicas adoptadas pelo dirigente de la reunión y el sicólogo clínico y que el lenguaje religioso es un privilegiado instrumento de dialogo. El entendimiento de esta lenguaje pode auxiliar los sicólogos a tratar adecuadamente con este fenómeno durante el proceso terapéutico.

Palabras-clave: Psicología de la Religion; Aconsejamiento Sicológico; Fenomenologia; Espiritismo.

\section{Introdução}

O tema "religião" é significativamente impactante na Psicologia, a ponto de não existir consenso em termos de sua definição ou mesmo das relações entre religião e Psicologia. Para Dalgalarrondo (2008), existem diferentes dimensões associadas a esse conceito: experiencial, espiritual, psicológica, sociológica, antropológica, histórica, política, teológica e filosófica. Dependendo do tipo de abordagem teórica ou do modelo de investigação que estiver sendo conduzido, cada um desses aspectos pode tomar relevâncias distintas.

Muitos autores apontam a importância da religião e da dimensão espiritual para o homem. Para Farris (2002), a religião fornece a ordem e a coerência à totalidade da vida; ela é doadora de significado à experiência e ao sofrimento humano (Dalgalarrondo, 2008). Ela fornece uma linguagem na qual é possível expressar as vivências espi- 
rituais do ser humano (Lopez, 2005), vivências essas que não podem ser ignoradas pela Psicologia que pretende estudar o ser humano nas suas mais diferentes dimensões: biológica, social, e porque não espiritual.

Entretanto, por muito tempo a Psicologia ignorou a dimensão espiritual do homem e muitos autores consideravam Psicologia e Religião como campos de conhecimento ou categorias de estudo totalmente separadas, dado que não haveria na religião nenhum aspecto compatível com o "científico" (Farris, 2002). Como consequência disso, percebe-se atualmente que os próprios psicólogos não conseguem expressar suas vivências espirituais em linguagem psicológica (Lopez, 2005) o que, segundo Giovanetti (1999), pode ocasionar uma perda da oportunidade de ajudar a própria pessoa a se compreender melhor. Paiva (1999) ressalta a importância de se realizarem estudos que possam descrever um comportamento religioso e analisar como ele funciona para ajudar os indivíduos e grupos a adaptar-se e a entender o mundo, e alguns trabalhos se dedicam a esse objetivo.

Como exemplos, temos trabalhos como os de Macedo, Fonseca \& Holanda (2007) que focalizam a prática do aconselhamento religioso em três vertentes religiosas brasileiras, encontrando similaridades desse com o aconselhamento psicológico (Santos, 1982). Lewgoy (2004) descreve uma pesquisa etnográfica em um centro espírita e constatou que grupos são fundamentais para a constituição da identidade dos espíritas. Observa-se, entretanto, que os comportamentos religiosos no contexto do Espiritismo Kardecista (Kardec, 1988, 2001) têm sido pouco investigados, sendo esse um campo de exploração em aberto, apesar da importância assumida por essa religião no Brasil nas últimas décadas, devido principalmente à figura do médium Chico Xavier (Lewgoy, 2001).

O Espiritismo Kardecista tem, dentre os seus princípios, a reencarnação, a possibilidade de comunicação com espíritos e a prática da caridade. Os espíritas oferecem tratamento que inclui passes (encarados como transmissão de energia), tipos de aconselhamento - que podem ser individuais ou em grupo - além de reuniões mediúnicas, nas quais espíritos são atendidos e orientados. Apesar de bastante difundida, a prática de reuniões mediúnicas tem sido pouco explorada na literatura Psicológica. Uma das razões para tal decorre do fato que, na maioria das casas espíritas, filiadas à Federação Espírita Brasileira (FEB), essas reuniões são sigilosas, e não são atualmente abertas ao público em geral. Mas o estudo e compreensão dessa prática são bastante relevantes para a Psicologia, pois nessas reuniões acontece um tipo de acolhimento que associamos ao que se compreende como um tipo de "aconselhamento", embora direcionado a um espírito que se comunica por meio de um médium, e em muitos hospitais psiquiátricos espíritas elas são utilizadas como parte do tratamento espiritual fornecido para desobsessão, que visa a diminuir a influência negativa de espíritos junto aos pacientes.
Alguns trabalhos destacam o sucesso desse tipo de tratamento (Jabert, 2008; Leão \& Lotufo Neto, 2007). Um estudo realizado por Drury (1993) aponta que é possível o uso da linguagem verbal no tratamento de psicóticos utilizando-se uma espécie de aconselhamento focado em questões religiosas. Isso parece acontecer nas reuniões mediúnicas, nas quais existem similaridades entre o aconselhamento religioso dado pelo dirigente da reunião ao espírito com o aconselhamento psicológico e outras estratégias utilizadas na Psicologia Clínica.

Para investigar esta hipótese o presente trabalho tem por objetivo caracterizar as reuniões mediúnicas, seus participantes, suas etapas e diálogos; observando as estratégias utilizadas pelo dirigente dessas reuniões e buscando entender suas articulações com o sofrimento humano e com a Psicologia Clínica, em suas diversas possibilidades, mas dando ênfase especial ao contexto da psicoterapia, do plantão psicológico e do aconselhamento psicológico. Apresentaremos, a seguir, os resultados obtidos a partir do registro observacional de uma reunião mediúnica em um centro espírita kardecista.

\section{Participantes e Coleta de Informações}

Primeiramente foi escolhido um centro espírita filiado à Federação Espírita do Paraná (FEP). Sendo assim, os procedimentos adotados e observados na reunião seguem as orientações dadas por essa federação ${ }^{1}$ e podem ser considerados representativos, pois por serem padronizados são, com certeza, similares aos que seriam observados em outros centros espíritas. Nesse centro, foi contatado o diretor dos grupos mediúnicos, que deu seu consentimento em nome da casa para realizar o trabalho e nos indicou um grupo para realizar a observação. Todos os participantes da reunião observada e o diretor da casa assinaram um Termo de Consentimento Livre e Esclarecido, rubricado pelo Comitê de Ética ${ }^{2}$ que aprovou a pesquisa.

O grupo mediúnico observado reúne-se semanalmente no centro espírita mencionado há quase três anos. É um grupo considerado novo no centro, visto existirem na casa grupos que se reúnem há mais de 15 anos. No dia da observação, estavam presentes 12 participantes, que serão identificados neste trabalho pela letra P, seguida de um número de 1 a 12, sendo que P1 será usado para designar o participante 1, P2 o participante 2, e assim por diante. Desses participantes, seis são homens e seis são mulheres, com idades variando entre 20 e 60 anos. Escolaridade e ocupação profissional são diversificadas.

Durante a observação foram utilizados apenas lápis e papel. Procurou-se registrar todos os eventos obser-

\footnotetext{
www.feparana.com.br

2 Pesquisa aprovada pelo Comitê de Ética em Pesquisa em Seres Humanos do Hospital Espírita de Psiquiatria Bom Retiro (HEPBR), Curitiba, Paraná. Folha de rosto: 291514, CAAE: 00007.0.087.000-09.
} 
vados, cronologicamente, anotando-se o tempo no qual ocorriam; técnica esta denominada "registro contínuo cursivo” (Danna \& Mattos, 1984). As anotações não focalizaram aspectos específicos da reunião. Os eventos aconteceram num ritmo lento o que facilitou a anotação e possibilitou um registro passo a passo da reunião bastante completo. O registro iniciou-se 30 minutos antes do início da reunião procurando também incluir os eventos ocorridos nesse período.

\section{Caracterização da reunião}

A partir das informações coletadas, o primeiro resultado que pode ser obtido foi a caracterização da reunião mediúnica considerando seus objetivos, sua ambientação e o local em que ocorre, bem como os participantes e as etapas de seu desenvolvimento, que serão descritos a seguir.

Objetivo: Os participantes da reunião mediúnica observada se reúnem com os objetivos estabelecidos pela FEB (2007), que são: fornecer assistência aos espíritos necessitados, educar as faculdades mediúnicas e praticar a caridade de forma anônima e desinteressada. O propósito é auxiliar, tanto encarnados como desencarnados, exercitar a humildade e a fraternidade. O Espiritismo é dualista, considera que além do nosso corpo físico, existe um espírito, que é a individualização do princípio inteligente e que sobrevive a morte. Ao longo do trabalho a palavra espírito é utilizada dentro desta concepção.

Horário, duração e frequência: As reuniões ocorrem uma vez por semana e seguem rigorosamente o horário, não sendo permitida a entrada de participantes atrasados. Observou-se que a porta foi fechada e a reunião iniciada pontualmente às 20h. Nenhum participante chegou atrasado. Mesmo os últimos a entrar na sala já se encontravam na casa anteriormente. A reunião durou uma hora e quarenta minutos. Recomenda-se uma duração de até duas horas (FEB, 2007).

Local: A reunião foi realizada numa sala específica, de maneira privada, na qual havia duas mesas justapostas, em volta das quais quinze cadeiras e um quadro branco. Em cima da mesa estavam distribuídas folhas de papel em branco e lápis, e no centro uma jarra de água e copos descartáveis.

Participantes e funções: Participam da reunião apenas trabalhadores com conhecimento espírita e que passaram por um período de pelo menos dois anos de estudo na casa. A equipe é formada pelos seguintes participantes (FEP, 2007).

- Dirigente da reunião: É o responsável pela condução do trabalho, sendo geralmente quem lidera e coordena o grupo. É o responsável por iniciar, encerrar, controlar o tempo etc. Na reunião observada, o dirigente é o participante P7.

- Esclarecedor ou dialogador: é quem dialoga com o espírito comunicante, faz o aconselhamento de acordo com a doutrina espírita. Foram identificados dois esclarecedores, P4 e P12.

- Médiuns ostensivos: de acordo com Kardec (1985) o médium ostensivo é aquele em quem a faculdade mediúnica se mostra bem caracterizada e se traduz por efeitos patentes, de certa intensidade, o que então depende de uma organização mais ou menos sensitiva. Eles incluem: médiuns psicofônicos (que transmitem a mensagem dos espíritos pela palavra), psicógrafos (que transmitem a mensagem dos espíritos por intermédio da escrita), videntes (capazes de ver os espíritos), audientes (capazes de ouvir os espíritos), etc. Neste relato correspondem aos participantes P1, P3, P6, P8 e P9.

- Equipe de apoio: São colaboradores que não possuem mediunidade ostensiva, chamados "equipe de sustentação” (ou médiuns de sustentação), e são responsáveis pelos passes, prece, irradiações e sustentação da corrente mental. Aqui, são os participantes P2, P5, P10, P11.

Posição ocupada pelos participantes: Observou-se que não há uma posição na mesa pré-definida para os participantes, eles chegam e sentam-se aleatoriamente. Exceção feita aos dirigentes e dialogadores. São dois os dialogadores que sentam equidistantes, próximos às extremidades das mesas. Observou-se que eles dividem o trabalho. Aquele que está mais perto do médium que está passando a comunicação é o responsável pelo diálogo.

Etapas: Foram observadas cinco etapas na reunião: 1) Fase preparatória na qual foram realizadas uma leitura inicial e prece; 2) Estudo e discussão na qual um trecho de um livro sobre qualidade na prática mediúnica foi lido e comentado por todos livremente; 3) Manifestação e esclarecimento dos espíritos; 4) Encerramento com prece final; e 5) Avaliação da reunião com comentários de todos sobre suas impressões durante a reunião. As etapas 1 e 2 ocuparam os vinte minutos iniciais da reunião, a etapa 3 , sessenta minutos e as etapas 4 e 5 os vinte minutos finais.

Ambiente: Observou-se, mesmo antes do início da reunião, um ambiente de silêncio e concentração. Antes de a reunião começar, os participantes cumprimentavam-se, mas após sentarem-se, mantiveram-se em silêncio lendo. Durante a etapa de estudo os comentários foram feitos essencialmente sobre o conteúdo lido e cada um esperava sua vez para falar. Durante a prece e leitura todos se mantiveram concentrados, a maioria de olhos fechados. Aconteceram três manifestações de espíritos, sendo uma 
por vez e nunca simultaneamente. O diálogo com um espírito foi conduzido do início ao fim sempre pelo mesmo dialogador. A primeira e terceira manifestações aconteceram através do médium P9. A segunda pelo médium P1, sendo os dois primeiros espíritos aconselhados pelo dialogador P12 e o terceiro por P4. Durante as manifestações, os demais participantes se mantiveram concentrados e em silêncio, com exceção do dirigente P7 e dos dialogadores $\mathrm{P} 4$ e P12 que se mantiveram o tempo todo de olhos abertos e atentos às necessidades do grupo. Durante a etapa de manifestação a iluminação da sala foi reduzida, apagando-se uma das lâmpadas.

\section{Análise das Informações Coletadas}

A análise das informações coletadas possibilita investigar semelhanças e diferenças existentes entre uma sessão mediúnica e uma sessão psicoterapêutica. O método utilizado para a análise é o qualitativo, com base fenomenológica, naquilo que diz respeito à qualidade dos dados explorados e ao modo de tratá-los e processá-los, pois os significados dos dados são estudados sem que medições sejam efetuadas (Gomes, 1998). O registro de observação foi analisado segundo o método fenomenológico e como resultados foram identificadas cinco unidades temáticas a serem utilizadas na análise. São elas: a) Objetivo da reunião; b) Setting terapêutico; c) Características do dialogador; d) Estratégias utilizadas; e e) Significado da reunião para o participante. Estes temas serão discutidos a seguir. Nesta discussão as falas de cada participante serão utilizadas, assim como a fala de cada espírito na ordem de comunicação: E1 (espírito da primeira comunicação), E2 (da segunda comunicação) e E3 (da terceira).

\subsection{Objetivos}

Tanto a reunião mediúnica quanto a psicoterapia compartilham um objetivo de auxiliar a pessoa que recorre ao processo. No primeiro caso, o objetivo é auxiliar espíritos sofredores, que na maioria das vezes ainda não se deram conta da sua nova situação ou que se acham vinculados a pessoas ou situações passadas, que poderíamos até mesmo chamar de traumáticas. A psicoterapia tem como objetivo auxiliar o cliente no enfrentamento do que traz como sendo um sofrimento psíquico. Vamos partir da clássica definição de psicoterapia para Wolberg (1988):

Psicoterapia é o tratamento, por meios psicológicos, de problemas de natureza emocional, no qual um especialista estabelece deliberadamente um relacionamento profissional com um paciente com o objetivo de: 1) Remover, modificar ou retardar sintomas existentes; 2) Intervir em modelos perturbados de comportamen- to, e, 3) Promover o crescimento e o desenvolvimento positivo da personalidade (p. 3).

A principal diferença, portanto, está no fato de que a psicoterapia pressupõe um contrato e uma relação de continuidade. A sessão terapêutica é apenas uma entre outras e faz parte de um processo. A sessão mediúnica é programada pelo "mundo espiritual", que traz espíritos que já estão em condições de serem ajudados (FEB, 2007). Funciona apenas como um "pronto socorro" (como seus participantes costumam dizer), que oferece um primeiro atendimento, na qual o espírito comunicante recebe vibrações dos médiuns encarnados para poder se reequilibrar e receber atendimento e tratamento posterior no plano espiritual. Isso fica bastante claro na fala do dialogador P12 ao Espírito 1 (E1 - espírito da primeira comunicação):

P12: "Tudo isso vai ser passado para você. Aqui é um pronto socorro. Você só recebe as primeiras orientações. Será conduzido a outro local e receberá tratamento, para compreender e se fortalecer" (diálogo com E1).

É interessante observar que o tratamento no plano espiritual inicia-se somente se o espírito aceitar e seguir com a equipe espiritual. Assim como na psicoterapia é necessário também o comprometimento da parte do outro (no segundo caso, do cliente).

E3: "É muito estranho, mas eu vou".

P4: "É confie e agradeça a Deus e a Jesus, por tê-lo encontrado e porque eles estão ai para te auxiliar. Confie e vai tranqüilo e compreenderá. Será ajudado".

E3: "Obrigado" (diálogo com E3).

Durante a avaliação P12 dá a entender que o espírito que não aceita o tratamento ou não consegue ampliar sua consciência para ser ajudado poderá ser trazido em outras reuniões na casa, mas isso não implica que o mesmo grupo ou dialogador o receberá. Não há, portanto, continuidade.

P12: "Ainda vai precisar retornar e ficar para tratamento (...) ele precisará ver que também tem sua parcela de culpa" (etapa avaliação).

A análise dos diálogos mostra que o atendimento em reuniões mediúnicas muito se assemelha à idéia do Plantão Psicológico, como o processo descrito por Bartz (1997) e Mahfoud (1999), no sentido que atende à problemática que se mostra no momento presente, no aqui e agora, e que visa aumentar a percepção da pessoa de seu contexto e de suas possibilidades. Na literatura, o Plantão Psicológico é descrito como um processo de atendimento criativo, que visa uma demanda de emergência, 
e que possui uma tríplice função: a) É terapêutica, como mobilizadora de insights; b) É preventiva, no sentido de evitar a cronicidade e; c) Pode ser preparatória ou sensibilizadora, para outros modos de tratamento ou atenção à demanda em questão (Bartz, 1997; Mahfoud, 1999; Tassinari, 1999).

No Plantão Psicológico, o objetivo é realizar um atendimento em até três sessões, privilegiando-se a sessão única, sendo que o cliente poderá voltar ao serviço sempre que desejar e será atendido pelo profissional disponível no momento. Isso se assemelha ao que acontece nas reuniões mediúnicas, que igualmente pode ser única, ou o espírito poderá voltar e ser atendido em outras sessões, mas não necessariamente com a mesma equipe mediúnica.

\subsection{Setting terapêutico e ambiente da reunião}

Algumas características são compartilhadas entre o ambiente da reunião e o que se procura em um setting terapêutico, como: privacidade, compromisso ético entre os participantes (de não comentarem fora o que se passa na reunião), tempo e frequência pré-determinados, acolhimento e sentimento de empatia para com o espírito. $\mathrm{O}$ grupo, durante as manifestações, permanece unido em torno do auxílio, em prece, irradiando e vibrando, fazendo o que os espíritas chamam de sustentação, ou seja, emitindo energias positivas, tanto para o espírito que se comunica, quanto para o médium e para o dialogador.

\subsection{O Dialogador e o Psicoterapeuta}

Muitos trabalhos na literatura apontam para as características desejadas para o psicoterapeuta e descrevem os principais desafios pertinentes a essa relação (Rogers, 1987; Craig, 1991; May, 2000; Lessa \& Novaes de Sá, 2006; Yalom, 2006). Todos consideram que a competência técnica, de acordo com o seu referencial teórico, e a experiência são fundamentais, mas também apontam outros fatores. Craig (1991), por exemplo, coloca que as principais características interpessoais para o terapeuta são: empatia, autenticidade, cordialidade, respeito e consideração positiva. Yalom (2006) reconhece a necessidade de autoconhecimento e do próprio psicoterapeuta fazer terapia. May (2000) também ressalta esse aspecto e diz que o terapeuta deve ser capaz de se desvencilhar de seus próprios valores e preconceitos, diminuindo as chances de realizar algum tipo de julgamento moral em relação ao cliente. Rogers, ao longo de sua obra coloca que o objetivo do terapeuta é participar da experiência imediata do seu cliente. Para isso é necessário que o terapeuta saiba escutar e observar, estando atento à relação e a sua interação com o cliente, característica a qual Rogers designa como congruência (Holanda, 2009).
Observa-se nos comentários anotados durante a observação da reunião mediúnica que seus participantes estão preocupados em adotar posturas semelhantes às mencionadas por esses autores e desejadas aos psicoterapeutas. As posturas adotadas podem ser observadas nas falas do dialogadores com os seguintes exemplos de:

- Acolhimento: Os três diálogos na etapa de manifestação de espíritos são sempre iniciados com a frase "Seja bem vindo".

P4: "Perceba que essa é uma casa de oração e estamos para ajudar, de uma maneira diferente, em uma época diferente" (diálogo com E3).

- Reconhecimento dos próprios limites, procurando verdade na relação:

P19: "Os que coordenam não são experts" (durante o estudo).

P19: “(...) Nós nos equivocamos” (diálogo com E2).

- Necessidade de estudo, de autoconhecimento:

P2: “(...) Por isso a necessidade desse trabalho e de também trabalharmos conosco" (no estudo).

Não basta realizar o trabalho com os espíritos, é preciso também trabalhar com cada um dos participantes. P2, ao fazer sua prece, pede para que todos aprendam humildade e que reconheçam a necessidade de estudo. Para participar de uma reunião mediúnica, todos os participantes passaram por pelo menos dois ou três anos de estudo da doutrina espírita, além do próprio estudo da mediunidade e continuam estudando em todas as reuniões. Foram treinados para sua função, realizando treinamentos oferecidos também para concentração e irradiação, assim como com cursos para as tarefas de dirigente e esclarecedor. Outros treinamentos foram oferecidos nos moldes da Federação Espírita do Paraná (FEP), para passe e atendimento fraterno. Pode-se dizer que a orientação filosófica que recebem é própria da doutrina espírita que se caracteriza por três aspectos: religioso, filosófico e científico (Kardec, 1988).

- Reciprocidade: apesar de ser centrada nas necessidades do espírito comunicante, a relação é bidirecional.

\section{P4: "Faculdade do espírito. Para ajudar e ser ajudado"} (no estudo).

P14: "Nós estamos crescendo e aprendendo juntos" (na prece).

- Empatia: tentam se colocar no lugar do outro ou compreender o outro, numa atitude caracterizada pelo "não-julgar". 
P4: “(...) Os irmãos que estão aqui têm as mesmas dificuldades que teremos quando sairmos daqui, não devemos julgar, eles nos ajudam a melhorarmos" (durante o estudo).

P19: "Entendemos o seu lado, compreendemos tudo que você passou. Não foi bom" (diálogo com espírito E2).

\subsection{Técnicas empregadas no trabalho mediúnico}

O psicólogo utiliza diferentes técnicas em seu consultório. A maioria dessas técnicas (não-privativas), entretanto - com exceção dos testes psicológicos (privativas do psicólogo) - são conhecidas e utilizadas por não psicólogos, tais como entrevistas, relaxamento, hipnose, técnicas de dinâmicas de grupo etc. As técnicas empregadas dependem do referencial teórico adotado e vale a pena ressaltar que elas são utilizadas pelo profissional de uma maneira sistemática que tem um sentido e motivo dentro do processo terapêutico, muito diferente do que pode ser o seu uso no senso comum.

Entretanto, foi observado que muitas dessas técnicas são também utilizadas na reunião mediúnica. Foi mencionado anteriormente que o dialogador e outros membros do grupo recebem treinamento, passando por um período longo de estudo da doutrina espírita. Além disso, eles recebem treinamento nas técnicas que deverão utilizar. Por exemplo: relaxamento, abstração propondo a utilização de imagens a serem focadas para facilitar a concentração, ampliação da consciência para se chegar ao transe mediúnico etc. O dialogador também recebe treinamento para condução do diálogo (na mesma direção de um aconselhamento) e muitos aspectos similares ao aconselhamento e à entrevista terapêutica podem ser verificados na etapa de manifestação e esclarecimento dos espíritos. A seguir, ilustra-se nos comportamentos e diálogos observados na reunião mediúnica, o emprego de algumas técnicas utilizadas na Psicologia Clínica.

Uma dessas técnicas é o relaxamento e uso da respiração. P12 pede para que os participantes se concentrem na respiração e procurem entrar em sintonia, acalmar os corações e realiza uma prece para abrir o trabalho mediúnico. Para auxiliar a concentração, muitas vezes utilizamse abstrações e imagens mentais, tais como mentalizar um lago, mentalizar Jesus etc. O próprio ambiente físico facilita a concentração, como um ambiente tranquilo, silencioso e com iluminação reduzida.

O relaxamento fornece um ambiente propício para a indução do transe mediúnico. Observou-se que durante o transe, ou manifestação dos espíritos, os médiuns permaneceram calmos e serenos. Muito embora a fisionomia e voz do médium se apresentassem um pouco alteradas, e expressarem as emoções do espírito, em nenhum momento os médiuns perderam a consciência ou o controle, permanecendo sempre sentados. Ao que tudo indica os transes observados nessa reunião fo- ram os que os espíritas chamam de "superficiais" (FEB, 2007). Nesse tipo de transe, o médium apenas recebe o pensamento do Espírito e o transmite. Isso foi comprovado durante a etapa de avaliação, na qual todos os médiuns recordaram os acontecimentos, dando a entender que durante o transe colaboraram na transmissão da mensagem do espírito comunicante e que permaneceram conscientes. Um outro ponto que merece destaque, é que além do ambiente favorável à indução do transe, parece que os médiuns sabem o momento correto para que ele aconteça. Eles ocorreram apenas na etapa de manifestação mediúnica, iniciada com a prece e comando do dirigente. Parece que cada médium é responsável por controlar seus transes, como se fosse uma auto-hipnose, pois não há transes concorrentes, e as manifestações seguem uma organização. Os espíritas dizem que essa organização é dada pelos dirigentes espirituais da reunião, que iniciam a etapa de ligação, de sintonia entre médium e espírito, ou seja, a indução ao transe, aproximando os espíritos do médium no momento correto. Nenhum ritual foi observado.

Verificam-se nos transes observados, semelhanças com as experiências agrupadas por Hilgard (1969) como Estados Alterados de Consciência (EAC), caracterizadas por um estado de sugestionabilidade aumentada, aumento de percepções de imagens, experiências sensoriais, diminuição da iniciativa e atitude de planejamento, e redução momentânea da capacidade de teste de realidade. Por exemplo, o médium P1 durante o transe e comunicação do espírito E2 sofre experiências sensoriais, diz sentir muita dor, tem a sensação real de ter os olhos perfurados.

E2: "Ai meus olhos. Por que fazem isso? (...)".

E2: "Alguma coisa entrou nos meus olhos, parecem dois pregos enormes (...)" (diálogo com E2).

O médium P9 diz durante o transe e comunicação do espírito E3 que tem dificuldades de perceber onde está e a realidade que o cerca.

\section{E3: "Estou procurando todos e não consigo encontrar o resto da corte (...)" \\ E3: "É muito estranho, vejo pessoas com roupas nobres, várias mulheres e concubinas, meu palácio. Que rou- pas estranhas são essas?" (diálogo com E3).}

Assim como algumas abordagens teóricas de cunho fenomenológico e existencial, o dialogador procura trabalhar com o aqui e agora. Os espíritos no início da comunicação parecem presos a uma cena do passado e o dialogador tenta trazê-los para o aqui e agora da sessão mediúnica. Veja um trecho da comunicação de E2. 
E2: "Ai meus olhos. Por que fazem isso? (...)".

E2: "Alguma coisa entrou nos meus olhos, parecem dois pregos enormes (...)".

E2: "Ando pelas paredes procurando uma porta. Mas só tem escadas, paredes, encontrei uma porta, entrei, achei uma cadeira e sentei. Mas não consigo ver nada".

P12: "Veja, você adentrou, sentou, e conversa conosCo".

E2: "Estou confusa, desde que entrei eu ouço coisas que não ouvia antes, nunca ninguém me ouviu antes (...)".

E2: "Só consigo ver aquilo vindo em direção a minha cabeça (...)".

P12: "E sua vida modificou?".

E2: "Sim. Não consigo ver".

P12: "E que mais? Sua família, seus amigos? Consegue falar com eles?".

E2: "Não sei não os vejo mais".

P12: "Por que você não os vê mais? Por que está sozinha entre aspas, porque Jesus está do seu lado. Consegue pensar sobre isso?".

E2: "Já. Agora é que percebi que eles não podem mais me ver desde aquele dia. Na verdade para eles eu morri".

P12: "Para eles sim, mas você conversa comigo. Nós não morremos. O espírito é imortal. Você acredita nisso?" E2: "Acredito, porque se eu não sinto mais dor, eu não devo ser aquele corpo que sentia dor".

P12: "Você está no corpo espiritual, você está viva. Os olhos machucados são do corpo físico, os do espírito podem ver".

E2: "Por isso encontrei a cadeira (...)".

E2: "Consigo ver, estou encontrando uma pessoa que gostava muito e tudo que eu pensava é verdade" (diálogo com E2).

Percebe-se no diálogo que no início o espírito permanecia fixo em uma cena; somente via escadas e algo vindo em sua direção, não conseguia ver e sentia dor nos olhos. Através do médium, entretanto, consegue se comunicar, e o dialogador chama a atenção do espírito para o que se passa com ele no aqui e agora da reunião; se ele não pode ver, como ele conseguiu entrar e sentarse? O que acontece com os conhecidos? O espírito consegue entender que pode enxergar ainda com os olhos do espírito, que continua vivo em outro corpo espiritual. Isso leva a uma mudança de comportamento, não mais vê a cena fixa de antes, agora vê uma pessoa amiga com a qual segue. A técnica utilizada tem como objetivo uma ampliação da consciência (na mesma direção do conceito de awareness para a Gestalt-terapia, como descrito por Kiyan, 2000), que leva a uma modificação, à elaboração de conteúdos reprimidos e a enxergar um novo universo e possibilidades de conhecimento, efeitos similares a uma catarse, em que ocorre não somente a exteriorização das emoções, chamada "catarse de integração", como temos no Psicodrama (Roja-Bermúdez, 1997).

Outra técnica empregada pelo dialogador é a entrevista, utilizada pelos psicólogos principalmente para obter informações, e principalmente para entender o paciente. Craig (1991) cita as principais técnicas de entrevista utilizadas, embora a preferência por uma delas se deva à orientação teórica do psicoterapeuta: questionamento, reflexão, re-exposição (ou paráfrase), esclarecimento, interpretação, reestruturação cognitiva (ou reframing, reformulação) etc.

Algumas dessas técnicas são observadas no diálogo com os espíritos e ilustradas na Tabela 1. Observa-se também nos diálogos da última linha desta tabela, o uso da abordagem rogeriana, conhecida como "resposta reflexo" ou "reflexo de sentimentos" (Rogers \& Kinget, 1977; Holanda, 2008, 2009). O dialogador, a partir dos pensamentos e sentimentos trazidos pelo espírito, procura não julgar e devolver os conteúdos que o espírito traz de uma maneira diferente que possibilite a reflexão.

Tabela 1: Técnicas de entrevista utilizadas pelo dialogador (Craig, 1991) - exemplos.

\begin{tabular}{|l|l|l|}
\hline $\begin{array}{l}\text { Questionamento "P12: "É a única coisa? O que } \\
\text { com objetivo de } \\
\text { clarificação ou } \\
\text { esclarecimento }\end{array}$ & $\begin{array}{l}\text { Para entender me- } \\
\text { (diálogo com E2). } \\
\text { lhor o que o espí- } \\
\text { rito está sentindo/ } \\
\text { trazendo. }\end{array}$ \\
\hline $\begin{array}{l}\text { Questionamento } \\
\text { no sentido de ex- } \\
\text { ploração }\end{array}$ & $\begin{array}{l}\text { "P12: E que mais? Sua famí- } \\
\text { falar com amiges?" } \\
\text { (diálogo com E2). }\end{array}$ & $\begin{array}{l}\text { Para explorar áre- } \\
\text { as e os limites do } \\
\text { paciente e verificar } \\
\text { seu grau de insight. }\end{array}$ \\
\hline $\begin{array}{l}\text { Reflexão e refra- } \\
\text { ming }\end{array}$ & $\begin{array}{l}\text { "P12: O que vai te trazer de } \\
\text { paz? Pense em você quanto } \\
\text { tempo de perseguição, de } \\
\text { sofrimento e de dores. Valeu } \\
\text { a pena?" } \\
\text { (diálogo com E1). } \\
\text { ghts e mudanças de } \\
\text { comportamento }\end{array}$ \\
\hline $\begin{array}{l}\text { "P12: Veja, você adentrou, } \\
\text { sentou e conversa conosco". } \\
\text { (diálogo com E2). }\end{array}$ & \\
\hline
\end{tabular}

\subsection{Significado da reunião para o participante}

Uma temática também identificada nos diálogos dos participantes durante as etapas de estudo e avaliação é o significado da reunião, e o que ela representa para os próprios médiuns. Constata-se pelas falas dos participantes que todos vêem a reunião mediúnica como uma oportunidade de serviço (como uma prática da caridade), de aprendizado, para melhorar a si próprio, para encontrar respostas para suas dificuldades:

"P4: (...) Para ajudar e ser ajudado. Quem é o desencarnado que se manifesta? Em breve serei eu também que vou estar precisando de ajuda e de prece. Os irmãos que estão aqui têm as mesmas dificuldades que teremos quando sairmos daqui e nos ajudam a melhorarmos" (no estudo). 
"P4: O mundo espiritual organiza a reunião de acordo com nossa condição, com o conhecimento que temos. Mexer na nossa consciência e trazer as respostas para dificuldades nossas" (no estudo).

P12: “(...) a Jesus amparo para aprender a servir, aprendendo também como nos devemos portar perante os que deixaram o corpo físico. São irmãos e necessitam de carinho, abraço amigo. Nós estamos crescendo e aprendendo juntos" (na prece).

\section{Discussão}

Nesta seção procura-se fazer uma discussão das semelhanças e diferenças observadas entre uma reunião mediúnica e a Psicologia Clínica, considerando uma aproximação com algumas das teorias psicológicas derivadas da linha fenomenológico-existencial: abordagem centrada na pessoa de Rogers (1987), Gestalt-terapia (Kiyan, 2000) e Psicodrama (Rojas-Bermudez, 1997).

Todas essas teorias baseiam-se em uma relação dialógica, que preza pela verdade e autenticidade. Portanto, tem como base o verdadeiro encontro e o estabelecimento de uma relação Eu-Tu (Buber, 1977). Esta característica também foi observada na reunião mediúnica. Observouse que o médium esclarecedor privilegia o ouvir, buscando perguntar e responder, e que os participantes emocionam-se e procuram compreender as emoções do espírito comunicante, acrescentando-lhe algo e ao mesmo tempo também reconhecem que aprendem, ou seja, que algo lhes foi acrescentado também.

Semelhante às abordagens fenomenológico-existenciais, não se procura explicar o porquê; não se interpreta, mas identifica-se no diálogo que a responsabilidade sempre cabe ao espírito e que ele é responsável por suas decisões e ações. $\mathrm{O}$ dialogador trabalha com aquilo que se manifesta no aqui e agora, sem conhecimento do passado ou futuro. Em comum com as linhas mencionadas, visa a organizar os conteúdos trazidos pelo espírito comunicante para permitir uma ampliação da sua consciência.

Uma diferença fundamental, entretanto, que precisa ser registrada, é que não se trata de um processo terapêutico com possibilidade de continuidade, como mencionado anteriormente. Ele se assemelha mais à idéia de um plantão psicológico, onde se faz um acolhimento de demandas imediatas, num processo no qual se privilegia a autonomização do sujeito.

Os transes observados, ao que tudo indicam são aqueles classificados por Dalgalarrondo (2008) como parciais. No dicionário (Houaiss \& Villa, 2001), a palavra transe é definida como um estado de alteração da consciência, marcado por reduzida sensibilidade a estímulos, perda ou alteração do conhecimento do que sucede à volta, suspensão das funções executivas e perda da capacidade de decisão com substituição da atividade voluntária pela au- tomática e do qual é difícil fazer sair o indivíduo. Pode ser provocado pela ação de drogas, da hipnose ou da meditação, entre outros. O transe provocado pela hipnose é utilizado por muitos psicólogos, desde Freud para revelar os conteúdos inconscientes, e até os dias de hoje para diversos tipos de tratamento, sendo uma técnica regulamentada pelo Conselho Federal de Psicologia (CFP), Resolução CFP 013/00 de dezembro de 2000.

Outra questão é que para a Psicologia, não existe o espírito comunicante, e os conteúdos manifestados são considerados conteúdos do próprio paciente. Fenômeno que também pode ocorrer na reunião mediúnica e que é chamado no Espiritismo de animismo (FEB, 2007), ou seja, quem se comunica nesse caso é o próprio espírito do médium sem haver a presença de um espírito (animismo puro). Muito embora não tenha ocorrido esse fenômeno na reunião observada, a literatura espírita mostra que ele é bastante comum. Nesse caso, o dialogador faz o esclarecimento normalmente, e apenas na fase de avaliação se comenta o fato, quando os videntes do grupo auxiliam a esclarecer a situação junto ao médium. A questão de se discutir a existência ou não da realidade transcendental está além do campo da Psicologia da Religião que não lida com a questão da existência ou não de Deus e de espíritos. O importante, portanto, é ressaltar que sendo ou não conteúdos do próprio médium, eles serão acolhidos na reunião mediúnica, e assim como na Psicologia, a distinção não é necessária para o tratamento do espírito (ou do médium, que nesse caso pode receber um tratamento mais prolongado, envolvendo várias reuniões).

O esclarecimento do espírito é bastante similar à prática do atendimento fraterno, que segundo Macedo et al. (2007) dá-se nos moldes de um aconselhamento psicológico concebido como uma série de contatos profissionais e diretos com um indivíduo, com o objetivo de lhe oferecer assistência no trato de aspectos pessoais ou relacionais, bem como na modificação de suas atitudes e comportamentos. Observa-se, no diálogo do esclarecedor, algumas semelhanças com o aconselhamento descrito por Rogers (1973), podendo-se citar: a necessidade de consideração positiva e incondicional, de compreensão empática e de autenticidade por parte do aconselhador. Macedo et al. (2007) apontam que essa forma de aconselhamento religioso surge em campo não-psicológico, retoma a visão holística de homem e acolhe a dimensão religiosa do ser humano, muitas vezes preterida pela Psicologia.

Como mencionado anteriormente, esse ponto está relacionado ao estudo relatado por Lopez (2005). Esse estudo mostra que os próprios psicólogos não conseguem expressar suas vivências espirituais em linguagem psicológica, possivelmente devido aos pressupostos de suas teorias de escolha. Os termos e explicações encontrados nas teorias, tendentes a um reducionismo ou causalismo, não dão conta de explicar o fenômeno, e os psicólogos conhecem apenas algumas posições da Psicologia 
que excluem as experiências religiosas do âmbito de seus estudos ou as focalizam como patológicas.

A religião, ao contrário, oferece conceitos e linguagens bem definidos, atribui sentido e valor; define horizontes, espaciais e temporais, inserindo-se na história; permite rever o passado, viver o presente e projetar o futuro (Dalgalarrondo, 2008). Essa linguagem parece ser bastante útil e bem sucedida em lidar com fenômenos observados na reunião que poderiam ser considerados psicopatológicos, fora do contexto do Espiritismo. Os resultados dessa pesquisa mostram que os espíritas de alguma maneira possuem um canal de comunicação tal qual especificado por Drury (1973) que permite o tratamento de psicóticos através da fala.

\section{Considerações Finais}

As limitações deste estudo apontam para a necessidade de se abrir novas perspectivas de pesquisa que toquem, tanto o campo da Psicologia da religião, quanto o da Psicologia clínica. Todavia, alguns elementos de reflexão se destacam desta pesquisa. Como exemplo de resultados, podemos concluir que as reuniões mediúnicas aparecem como uma importante prática religiosa a ser considerada na Psicologia e no contexto de saúde mental. Uma maior aproximação da ciência psicológica desses contextos religiosos surge como possibilidade real para a compreensão de inúmeros fenômenos psicopatológicos.

Vale a pena ressaltar a importância de se conhecer mais sobre a prática mediúnica por parte dos diferentes profissionais e psicólogos, e suas relações com o tratamento psicoterapêutico. Para isso fica a sugestão de Lopez (2005) para os psicólogos:

Simbolizar e articular sentidos para a espiritualidade em um campo cultural, ampliar a consciência da própria vivência, discriminar as suas nuances. Possibilita ao psicólogo explorar e reconhecer símbolos integrados a sua vida e os diferentes sentidos dela oriundos, revisitando, muitas vezes, o próprio trajeto individual (p. 157-158).

Isto lhe abrirá um infinito de possibilidades e de interpretações. Assim sendo, uma possível direção para continuidade desse trabalho seria realizar uma pesquisa junto aos psicólogos para avaliar como a orientação religiosa vem sendo considerada e trabalhada no consultório, em particular a mediunidade, relacionando esse trabalho a suas próprias vivências religiosas. Outro caminho importante seria avaliar como que a prática clínica pode ser incorporada aos contextos religiosos, como são os casos dos diversos modelos de "aconselhamento religioso".

Analisando-se os comentários dos participantes, observa-se que eles consideram a participação em reuniões mediúnicas como um apoio na solução de suas dificuldades e uma oportunidade de crescimento e aprendizado. Seria, portanto, interessante realizar uma pesquisa, por meio de entrevistas, para ver como eles experienciam sua mediunidade e o efeito em suas vidas associado à participação nas reuniões. Outro trabalho futuro seria o de relacionar a prática mediúnica com certas características de personalidade dos participantes.

Percebe-se com essas possibilidades que há inúmeros desdobramentos possíveis para o trabalho e que longe se está de esgotar a discussão das questões aqui levantadas. A importância deste trabalho é a de contribuir ou motivar para o aprofundamento dessas questões que são de fundamental importância para a Psicologia e que precisam ser compreendidas para que os psicólogos possam lidar adequadamente com esse fenômeno religioso durante o processo terapêutico.

\section{Referências}

Bartz, S. S. (1997, janeiro/julho) Plantão Psicológico: Atendimento criativo à demanda de emergência. Interações, 2(3), 21-34.

Buber, M. (1977) Eu e Tu. São Paulo: Cortez e Moraes Ltda.

Craig, R. J. (1991). Entrevista Clínica e Diagnóstica. Porto Alegre: Artes Médicas.

Dalgalarrondo, P. (2008). Religião, psicopatologia e saúde mental. Porto Alegre: Artmed.

Danna, M. F., \& Matos, M. A. (1984). Ensinando Observação: Uma Introdução. São Paulo: Edicon.

Drury, M. O. C. (1973). Madness and Religion. The danger of words. London: Ed. Routledge and Kegan Paul.

Farris, J. R. (2002). Psicologia e religião. A relação entre religião e saúde mental. Estudos de Religião, 22, 163-178.

FEB (2007). Estudo e Prática da Mediunidade - Programa II. Brasília, DF: Federação Espírita Brasileira.

Giovanetti, J. P. (1999). O sagrado e a experiência religiosa na psicoterapia. Em M. Massimi \& M. Mahfoud (Orgs.), Diante do mistério: psicologia e senso religioso (pp. 87-96). São Paulo: Loyola.

Gomes, W. (1998). Fenomenologia e Pesquisa em Psicologia. Porto Alegre: Editora da Universidade Federal do Rio Grande do Sul.

Hilgard, E. R. (1969). Pain as a puzzle for psychology and physiology. American Psychologist, 24, 103-113.

Holanda, A. F. (2008). A Instrumentalização Terapêutica na Perspectiva de Carl Rogers. Em A. Pimentel \& A. C. Moreira (Orgs), Psicologia. Instituição. Cultura (pp.61-78). Belém: Editora Amazônia.

Holanda, A. F. (2009). A perspectiva de Carl Rogers acerca da Resposta Reflexa. Revista do Nufen, 1(1), 40-59. 
Houaiss, A., \& Villa, M. S. (2001). Dicionário Houaiss da Língua Portuguesa. Rio de Janeiro: Objetiva.

Jabert, A. (2008). De médicos e médiuns: Medicina, Espiritismo e loucura no Brasil da primiera metade do século XX. Tese de Doutorado, Casa de Oswaldo Cruz/ Fiocruz, Pós-graduação em História das Ciências e da Saúde, Rio de Janeiro.

Kardec, A. (1985). O livro dos médiuns. Brasília: Federação Espírita Brasileira.

Kardec, A. (1988). O livro dos espíritos. Araras: Instituto de Difusão Espírita.

Kardec, A. (2001). O Evangelho segundo o espiritismo. São Paulo: Lake.

Kiyan, A. M. M. (2000) E a Gestalt Emerge. Vida e Obra de Frederick Perls. São Paulo: Ed Altana.

Leão, F. C., \& Lotufo Neto, F. (2007). Uso de práticas espirituais em instituição para portadores de deficiência mental. Revista de Psiquiatria Clínica, 42(1), 54-59.

Lessa, J. M., \& Novaes de Sá, R. (2006). A Relação Psicoterapêutica na Abordagem Fenomenológica-Existencial. Análise Psicológica, 24(3), 393-397.

Lewgoy, B. (2001). Chico Xavier e a cultura brasileira. Revista de Antropologia, 44(1), 53-116.

Lewgoy, B. (2004, julho/dezembro). Etnografia da Leitura num Grupo de Estudos Espírita. Horizontes Antropológicos, 10(22), 255-282.

Lopez, M. A. (2005). A espiritualidade e os psicólogos. Em M. M. Amatuzzi, Psicologia e espiritualidade (pp. 147-159). São Paulo: Ed. Paulus.

Macedo, D. S., Fonseca, C. M. M., \& Holanda, A. F. (2007). Um Estudo Comparativo de Aconselhamento Religioso em três vertentes religiosas brasileiras. Revista da Abordagem Gestáltica, 13(2), 206-215.

Mahfoud, M. (1999). Plantão Psicológico: Novos Horizontes. São Paulo: Ed C.I. Ltda.

May, R. (2000). A Arte do Aconselhamento Psicológico. Petrópolis: Ed Vozes.

Paiva, G. J. (1999). Psicologia e religião na discussão atual. Estudos de religião, 16, 15-26.

Rogers, C. (1973). Psicoterapia e consulta psicológica. Lisboa: Moraes Editores.

Rogers, C. R., \& Kinget, G. M. (1977). Psicoterapia e Relações Humanas. Belo Horizonte: Interlivros.

Rogers, C. R. (1987). Tornar-se Pessoa. São Paulo: Ed. Martins Fontes.

Rojas-Bermúdez, J.G. (1997) Introdução ao Psicodrama. São Paulo: Ed. Mestre Jou.

Santos, O. B. (1982). Aconselhamento psicológico e psicoterapia. São Paulo: Pioneira.
Tassinari, M. A. (1999). Plantão Psicológico Centrado na Pessoa como Promoção de Saúde no Contexto Escolar. Dissertação de Mestrado em Psicologia, Universidade Federal do Rio de Janeiro, Rio de Janeiro.

Wolberg, L. (1988). The Technique of Psychotherapy. New York: Grune \& Sttraton.

Yalom, I. D. (2006). Os Desafios da Terapia: reflexões para pacientes e terapeutas. Rio de Janeiro: Ediouro.

Silvia Regina Vergílio - Graduanda em Psicologia pela Universidade Federal do Paraná, além de Bacharel em Ciências da Computação pela Universidade de São Paulo (Campus São Carlos), Mestre e Doutora em Engenharia Elétrica pela Universidade Estadual de Campinas (Unicamp), e Professora do Departamento de Informática da Universidade Federal do Paraná. Endereço Institucional: Universidade Federal do Paraná (UFPR) - CP: 19081. Centro Politécnico, Jardim das Américas. Curitiba, PR. CEP: 81531-970. Email: silvia@inf.ufpr.br

Adriano Furtado Holanda - Doutor em Psicologia pela PUC-Campinas e Professor Adjunto da Universidade Federal do Paraná. Email: aholanda@yahoo.com

Recebido em 10.07.10 Primeira Decisão Editorial em 15.09.10 Aceito em 07.10.10 